\title{
Abordagem qualitativa nas pesquisas em Gerenciamento em Enfermagem: revisão integrativa
}

\author{
Rogério Silva Lima, M.Sc.*, Eliana Bernardes Lourenço, D.Sc.**, Larissa Mayre Monteiro dos Santos***
}

\begin{abstract}
*Enfermeiro, Especialista em Enfermagem em Urgência e Emergência (Modalidade Residência) pela PUC-Campinas, Professor Assistente da Escola de Enfermagem Wenceslau Braz-EEWB-MG, **Psicóloga, Pedagoga, Professora Adjunta da Universidade Federal de Alfenas, UNIFAL-MG, ***Discente do $6^{\circ}$ periodo do Curso de Graduação em Enfermagem da Escola de Enfermagem Wenceslau Braz, EEWB, Itajubá, $M G$
\end{abstract}

\section{Resumo}

O estudo objetivou conhecer a produção científica da Enfermagem brasileira no tocante à temática do gerenciamento em enfermagem com o uso da abordagem de pesquisa qualitativa. Trata-se de uma revisão integrativa efetuada por meio de uma busca bibliográfica nas bases de dados Medline e Lilacs com os Descritores em Ciências de Saúde: Pesquisa em administração em Enfermagem, Gerência e Enfermagem, separadas pelo operador boleano "and". Obteve-se 20 artigos que compuseram o corpus de análise, 15 artigos não apresentaram referencial teórico para realizar as análises, predominou como método de coleta dos dados a entrevista semiestruturada e como técnica para análise dos dados a análise de conteúdo. O uso da abordagem qualitativa na pesquisa em Gerenciamento em Enfermagem está em crescimento acompanhando o processo de transição de um paradigma positivista para um paradigma voltado às abordagens compreensivas.

Palavras-chave: gerência, Enfermagem, pesquisa qualitativa.

\section{Abstract \\ Qualitative approach on nursing management research: integrative review}

The aim of this study was to know the Brazilian Nursing scientific production on Nursing Management using qualitative approach. This is an integrative review and data were collected in Medline and Lilacs electronic data bases with Health Science Descriptors: Nursing Administration Research, Management and Nursing. The analysis corpus was composed by 20 publications. 15 articles did not have theoretical approach to carry out the analysis. The semi-structured interview was predominantly used as method of data collection and to analyze data, content of analysis was used. The use of qualitative research in nursing management is increasing following the transition from a positivist paradigm to a paradigm aiming at comprehensive approaches.

Key-words: management, Nursing, qualitative research. 


\section{Resumen}

\section{La investigación cualitativa en la gestión de enfermería: una revisión integrativa}

Este estudio tuvo como objetivo conocer la producción científica de la Enfermería brasileña en relación con el tema de la Gestión de Enfermería utilizando la investigación cualitativa. Se trata de una revisión integrativa que se realizó a través de búsqueda bibliográfica en la base de datos Medline y Lilacs con los Descriptores en Ciencias de la Salud: Investigación en Enfermería en Administración, Gerencia y Enfermería. Se obtuvieron 20 artículos que conformaron el corpus de análisis, 15 artículos no tenían marco teórico. El método predominante para la recolección de datos fue la entrevista semiestructurada. El análisis de contenido fue el más utilizado para organizar y analizar los datos. El uso de la investigación cualitativa en la Gestión de Enfermería sigue creciendo acompañando el proceso de transición de un paradigma positivista para un paradigma con abordaje comprehensivo.

Palabras-clave: gerencia, Enfermería, investigación cualitativa.

\section{Introdução}

O trabalho em enfermagem é multidimensional em sua natureza e não se restringe ao âmbito do assistir diretamente o indivíduo em situação de demandas de saúde, mas abarca outras atribuiçóes que, direta ou indiretamente, implicam no ato cuidativo. Nesse contexto, o processo de trabalho gerencial do enfermeiro se reveste de singular importância, dada à multiplicidade de interfaces com que esta dimensão se relaciona com os demais aspectos do trabalho em saúde.

A gerência pode ser entendida como um processo de trabalho específico que possui objeto e objetivos inter-relacionados, sendo seus componentes os recursos humanos e a organizaçáo do trabalho. Possui como finalidades a obtenção e a manutenção de recursos humanos qualificados e a sistematização do trabalho, visa também às condições adequadas para atender à saúde dos indivíduos. Os meios e instrumentos do processo de trabalho gerencial do enfermeiro são: recursos físicos, financeiros, materiais e os saberes administrativos, com habilidades necessárias ao planejamento, à organização, à coordenação e ao controle das funçôes pertinentes à gerência [1].

A gerência em enfermagem é resultante da influência histórica da institucionalização do hospital e da implantaçáo do modelo biomédico de assistência à saúde, tal influência contribuiu para a conformação da força de trabalho em enfermagem a partir de sua divisão técnica e social [1]. A complexidade da função gerencial do enfermeiro e sua repercussão sobre os mais variados aspectos nos âmbitos assistencial, administrativo e socioeconô- mico torna premente a necessidade de realizar mais estudos que abordem o tema nos diversos contextos da realidade brasileira.

A pesquisa em enfermagem que leva em conta a temática do gerenciamento tem apresentado aumento significativo na realidade brasileira [2-3]. As variadas vertentes técnicas, políticas, relacionais e sociais que envolvem a gerência em enfermagem permitem diferentes olhares sobre o objeto de estudo e, consequentemente, diferentes posturas epistemológicas, abordagens e métodos de pesquisa que possibilitam a aproximação para com o fenômeno que se pretende investigar.

Em virtude disso o gerenciamento em enfermagem visando à prática social, inserido em um contexto específico e vinculado ao processo de relaçôes sociais em um grupo específico, condiciona-se e está condicionado à dinâmica social [4]. Ressalta-se que as relações humanas em sua dimensão social são complexas, dinâmicas, instáveis, mutáveis e passageiras. Seu caráter dinâmico requer que o pesquisador se aproxime com base em uma análise pautada não apenas naquilo que pode ser observado e quantificado, mas sim na apreensão da relação que ocorre entre os atores envolvidos. Acrescenta-se que a complexidade de que se reveste as relaçóes implica na impossibilidade de assumir que os conhecimentos produzidos não estáo impregnados pelos seus atributos de caráter social, cultural e político [4].

A concepção de gerência em enfermagem que leva em conta sua subjetividade intrínseca abre caminho para uma posição epistemológica que favorece uma postura crítica quanto às noçóes e neutralidade e objetividade consideradas como critério essencial de cientificidade [5] 
Os temas que se vinculam ao gerenciamento, particularmente quando se pensa a gerência em enfermagem em relação as suas dimensôes política, comunicativa e de desenvolvimento de cidadania [6], descortinam um solo fecundo para investigação fundamentada em outras abordagens de pesquisa que não necessariamente se atêm ao modelo proposto pelo paradigma positivista, ainda dominante na ciência, particularmente nas ciências da saúde.

Nesse sentindo, os métodos qualitativos surgiram no âmbito das Ciências Humanas e Sociais para atender às suas peculiaridades, haja vista não ser possível estudar os fenômenos do mundo social e psicológico unicamente por meio de análises estritamente quantitativas.

$\mathrm{O}$ recurso metodológico qualitativo na área da saúde oferece ao pesquisador a possibilidade de compreender a maneira pela qual os indivíduos pensam e reagem frente a determinadas situaçóes, de compreender a dinâmica e as mobilizaçóes das pessoas como, por exemplo, de auxiliar na compreensão dos sentimentos, valores, crenças e atitudes do outro. Esse conhecimento possibilita ao pesquisador planejar açóes que valorizam mais o "ser" como sujeito de sua açáo, pois consegue, com os dados coletados, conhecer em maior profundidade a experiência vivida pelos sujeitos [7].

No aspecto do gerenciamento em enfermagem a abordagem de pesquisa qualitativa pode favorecer a aproximação para compreensáo da teia de relaçóes que envolvem a práxis do enfermeiro e descortinar questôes que não são passíveis de entendimento unicamente a partir de dados numéricos.

O cenário delineado neste texto favoreceu a formulação do objetivo deste estudo, o qual foi conhecer a produçáo científica da Enfermagem brasileira no tocante à temática do gerenciamento em enfermagem com o uso da abordagem qualitativa veiculada em periódicos nacionais.

\section{Métodologia}

Trata-se de um estudo bibliográfico documental realizado pelo método da revisão integrativa. Esta abordagem é a mais ampla referente às revisóes e permite a inclusão de estudos de diversas naturezas para aproximação da compreensão do fenômeno que se objetiva analisar [8].

A pesquisa pautou-se pela seguinte questão norteadora: como tem sido o uso da abordagem qualitativa nas pesquisas em Gerenciamento em Enfermagem no Brasil?

A busca bibliográfica foi efetuada nas bases de dados Medical Literature Analysis and Retrieval System Online (Medline) e Literatura Latino-Americana e do Caribe em Ciências da Saúde (Lilacs), com os Descritores em Ciências de Saúde (DeCS): "Pesquisa em administração em Enfermagem”, "Gerência” e "Enfermagem", separadas pelo operador boleano "and". A coleta de dados ocorreu no mês de maio de 2012. Os critérios de inclusão foram: artigos originais, publicados em periódicos nacionais de Enfermagem com classificação no Sistema Qualis da CAPES (Coordenação de Aperfeiçoamento de Pessoal de Nível Superior), que tivessem resumo disponível em suporte eletrônico. Os artigos deveriam tratar da temática referente ao gerenciamento de enfermagem e utilizar a abordagem qualitativa como ferramenta de análise. Os critérios de exclusão foram: editoriais, monografias, teses, dissertações, manuais, artigos publicados em periódicos internacionais e artigos que, apesar de abordarem a questão do gerenciamento em enfermagem, não utilizaram a abordagem qualitativa.

Neste estudo não houve a necessidade de aprovação por Comitê de Ética em Pesquisa, pois foram usados dados de livre acesso.

Realizou-se a leitura dos títulos e resumos dos artigos, para pré-seleção daqueles que atendiam aos critérios de inclusão mencionados, quando o resumo náo deixava claro o tipo de abordagem utilizada pelos autores, o texto era lido na íntegra.

A pré-seleçáo resultou em 33 (trinta e três) publicaçóes, que após leitura dos textos na íntegra, totalizaram 20 artigos que compuseram o corpus de análise.

Os artigos selecionados foram lidos novamente com ênfase na identificação dos seguintes aspectos: ano de publicação, periódico publicado, referencial teórico, instrumento e método de análise de dados.

Por referencial teórico entende-se a visão de mundo que o pesquisador utiliza para analisar os dados, ou seja, o pressuposto filosófico que fundamenta a concepção de ciência, de mundo e de homem. Orientação metodológica nessa pesquisa foi compreendida como o conjunto de procedimentos adotados para organização, exploração e análise do material empírico obtido a partir da coleta de dados. Instrumento de coleta dos dados nesse estudo foi tomado como a técnica por meio da qual os dados foram obtidos. 


\section{Resultados e discussão}

Os vinte artigos selecionados estavam distribuídos entre os seguintes periódicos: Revista Brasileira de Enfermagem (sete artigos), Revista de Enfermagem da UERJ (quatro artigos) Texto \& Contexto Enfermagem (dois artigos), Revista Eletrônica de enfermagem (dois artigos) e Revista da Escola de Enfermagem da USP, Revista Nursing, Revista de Enfermagem Ana Nery, Revista Gaúcha de Enfermagem e Revista APS (todos com um artigo).

A grande maioria dos artigos (18 artigos) teve sua data de publicação nos últimos 10 anos (Figura 1). A pesquisa em gerenciamento em enfermagem com uso de abordagem qualitativa no Brasil tem apresentado crescimento. Este achado é corroborado pelo estudo de Kurgant e Ciampone [3] no qual as autoras constataram que a pesquisa nessa área de concentração tem se aberto a novos paradigmas de conhecimento voltados para as concepçôes mais compreensivas do que positivistas.

Figura 1 - Distribuição da frequência dos artigos sobre Gerenciamento de Enfermagem com uso de abordagem qualitativa, por período (em anos).

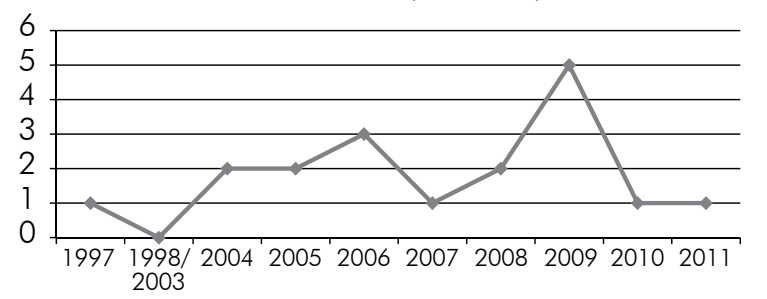

Acredita-se que a construção do conhecimento científico deve ser entendida como uma atividade edificada num tempo e espaço específicos e permeada por uma realidade que é também intersubjetiva. Desse modo precisam ser considerados os aspectos simbólicos que revestem os fenômenos. Assim, faz-se necessário não somente estudar o fenômeno em si, mas também compreender o significado a ele atribuído seja individual ou coletivo. No âmbito da gerência entendida como uma prática social, o enfermeiro se situa no espaço dialógico de interação no seu processo de trabalho, o que exige desse profissional, além de capacidade de gerencia técnica, a gerência das relações [9]. Nesse sentido a temática pode requerer outras concepçóes de pesquisa, com raízes na sociologia, antropologia e psicologia social, que dêem conta da investigação desses aspectos.

O instrumento de coleta de dados mais utilizado foi a entrevista semiestruturada (Figura 2). Era esperado que a entrevista semiestruturada tivesse predominância, pois na pesquisa qualitativa essa técnica tem sido usada em quase todas as tradiçóes de investigação [10]. Este tipo de entrevista privilegia o alcance dos objetivos, uma vez que favorece a identificação da interface subjetiva dos entrevistados.

Figura 2 - Distribuição da frequência da utilização dos instrumentos de coleta de dados nos artigos sobre $\mathrm{Ge}$ renciamento de Enfermagem com uso de abordagem qualitativa.

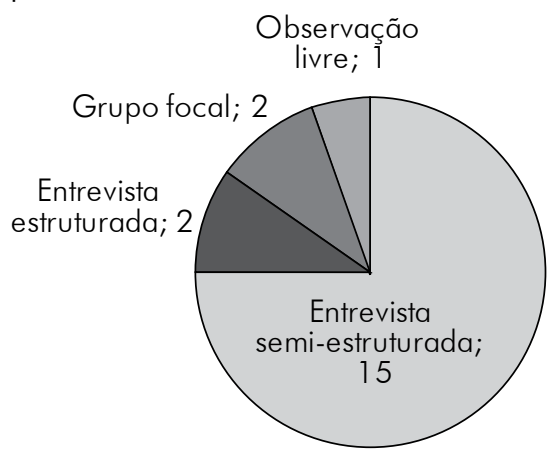

O referencial teórico utilizado para as análises, como é mostrado na Figura 3 não foi apresentado por 15 artigos e nos 5 artigos o que apresentaram foram utilizados: análise institucional de Lourau (um artigo), análise institucional de Lourau e socioanálise (um artigo), processo de trabalho em saúde (um artigo), interacionismo simbólico (um artigo), teoria geral dos sistemas e concepção Simoniana de administrar (um artigo).

Figura 3 - Distribuição da frequência dos referenciais teóricos utilizados nos artigos sobre Gerenciamento de Enfermagem com uso de abordagem qualitativa.

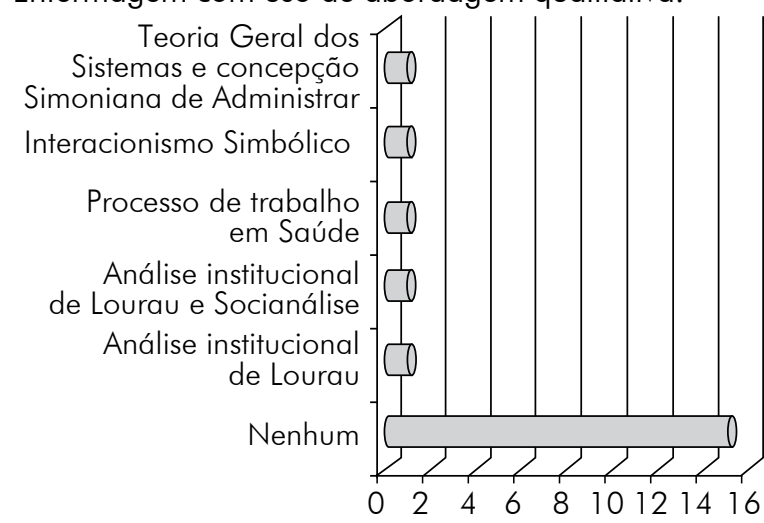

Frente aos desafios de novos problemas de pesquisa a enfermagem tem acompanhado o movimento, que tem ocorrido nas ciências em geral, na procura de superar a dicotomia realismo-subjetivismo representada no pensamento filosófico empirista e 
idealista, do paradigma dominante que ainda preside à ciência moderna como um modelo totalitário. Esse movimento, também denominado de "crise" por Santos [5], deve-se, dentre outros fatos, à existência de uma pluralidade de condiçóes sociais e teóricas que requerem outras abordagens metodológicas para darem acesso ao real e dêem conta de responder às questóes eminentemente humanas. Tais abordagens metodológicas se pautam em raízes teóricas e filosóficas que não se sustentam na distinção dicotômica entre ciências naturais e sociais, ao contrário, revalorizam e priorizam os estudos humanísticos voltados à compreensão e não à manipulação do mundo [5].

No tocante ao método de organização e análise dos dados predominou a análise de conteúdo (7 artigos) e métodos derivados desse pressuposto metodológico: categorização ( 4 artigos) e análise temática (4 artigos), nos demais 5 artigos foram utilizados os seguintes métodos: análise institucional (2 artigos), brainstorming ( 1 artigo), não apresenta (1 artigo) e teoria fundamentada nos dados (1 artigo), como mostra a Figura 4.

Figura 4 - Distribuição da frequência dos métodos de organização e análise dos dados utilizados nos artigos sobre Gerenciamento de Enfermagem com uso de abordagem qualitativa

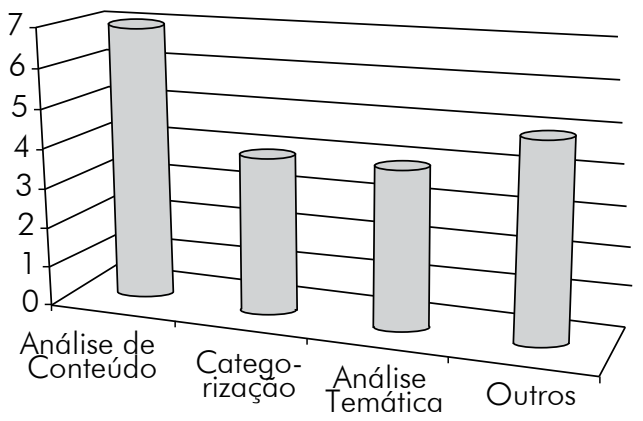

A análise de conteúdo (AC) de Laurence Bardin como método de análise tem sido crescente na área de enfermagem, de acordo com Caregnato e Mutti [11]. AC pode assumir diferentes perspectivas de acordo com o objeto de estudo [12]. Este método é conceituado por Bardin [13] como "um conjunto de técnicas de análise das comunicaçóes visando obter, por procedimentos sistemáticos e objetivos de descrição do conteúdo das mensagens, indicadores (quantitativos ou não) que permitam a inferência de conhecimentos relativos às condiçôes de produção/ recepção [...] destas mensagens".

Esse método de análise pressupóe a forma de manter a coesão frente à heterogeneidade do objeto de estudo. Desenvolvida no início do séc. XX, procedente de uma longa tradição de interpretação de texto, esteve voltada inicialmente para estudos de abordagem quantitativa, procurando conferir maior objetividade ao estudo. Todavia este movimento foi batizado pelo rigor metodológico com vistas à garantia da objetividade frente à heterogeneidade do objeto, herdeiro do iluminismo e de cunho positivista [14].

A partir da raiz histórica da AC, outros desdobramentos puderam ser assumidos como análise categorial, da qual pode emergir a análise temática, quando as categorias são construídas a partir dos temas que emergem do texto [12].

A multiplicidade de conceitos que circunscrevem a $\mathrm{AC}$ pode tornar a prática e o uso do método pouco claro quando se omitem alguns cuidados metodológicos próprios. Nesta pesquisa chama a atenção o fato de a maioria dos artigos que fizeram uso desse método de análise não ter apresentado com clareza o referencial teórico que norteou a interpretação dos dados.

Cabe ressaltar que cada tipo de análise determina procedimentos que são vinculados aos objetivos do estudo [12] de modo que, por ocasiáo do desenvolvimento da pesquisa de natureza qualitativa, tais aspectos precisam ser bem delineados. Assim a análise recai sobre a compreensão e internalização dos termos filosóficos e epistemológicos que fundamentam a investigação em que teoria, métodos e técnica se dialogam mutuamente [15].

\section{Conclusão}

A revisão integrativa das publicações científicas no Brasil sobre gerenciamento em Enfermagem com o uso da abordagem qualitativa permitiu o acesso ao modo como tem sido usada à referida abordagem.

A abordagem qualitativa no gerenciamento em Enfermagem está em crescimento acompanhando o movimento de busca por novos horizontes e concepçôes de pesquisa que não se assentam no paradigma positivista, porém a maioria das publicaçóes não apresenta com clareza o referencial teórico que norteia a análise dos dados. Denota-se, portanto, que o desenvolvimento das pesquisas qualitativas com a temática em gerenciamento tem avançado à medida que os estudiosos de enfermagem têm se apropriado e se familiarizado com outras abordagens de estudo.

Faz-se necessário que mais trabalhos sejam realizados com relação a outras temáticas da área de 
enfermagem para que se conheça o estado da arte nesse aspecto, e contribua para que os pesquisadores utilizem outras teorias, métodos e técnicas de pesquisa que se complementam e mutuamente se sustentam com o objetivo de preencher as lacunas de conhecimento na área.

\section{Referências}

1. Peres AM, Ciampone MHT. Gerência e competências gerais do enfermeiro. Texto Contexto Enferm 2006;15(3):492-9.

2. Lima CKG, Sanna MC. A trajetória da produção científica do Curso de Especializaçáa em Gerenciamento de Serviços de Enfermagem da UNIFESP. Rev Bras Enferm 2008;61(3):325-29.

3. Kurcgant P, Ciampone MHT. Pesquisa na área de gerenciamento em enfermagem no Brasil. Rev Bras Enferm 2005;58(2):161-4.

4. Zavaglia T. Critérios de validade científica nas ciências humanas. Revista do Centro de Educação 2008;33(3):469-80.

5. Santos BS. Um discurso sobre as ciências. 12aed. Porto: Afrontamento; 2001.

6. Mishima SM, Villa TCS, Silva, EM, Gomes, ELR, Anselmi, ML, Pinto, IC, Almeida, MCP. Organiza- ção do processo de trabalho gerencial no trabalho em saúde pública. In: Almeida MCP, Rocha SMM, eds. O trabalho de enfermagem. São Paulo: Cortez; 1997. p. 251-96.

7. Neves, JL. Pesquisa Qualitativa: características, usos e possibilidades. Caderno de Pesquisa em Administraçáo 1996;1(3):1-5.

8. Souza MT, Silva MD, Carvalho R. Revisão integrativa o que é e como fazer. Rev Einstein 2010;8(1):102-6.

9. Urbanetto JS, Capella BB. Processo de trabalho em enfermagem: Gerenciamento das relaçôes interpessoais. Rev Bras Enferm 2004;57(4):447-52.

10. Polit FD, Beck CT, Hungler BP. Fundamentos de pesquisa em enfermagem: avaliação de evidências para a prática da enfermagem. $7^{\mathrm{a}}$ ed. Porto Alegre: Artmed; 2011.

11. Caregnato RCA, Mutti R. Pesquisa qualitativa: análise de discurso versus análise de conteúdo. Texto Contexto Enferm 2006;15(4):679-84.

12. Oliveira DC. Análise de Conteúdo Temático-Categorial: uma proposta de sistematização. Rev Enferm UERJ 2008;16(4):569-76.

13. Bardin L. Análise de conteúdo. Lisboa: Ediçôes 70; 1977.

14. Rocha B, Deusdará D. Análise de Conteúdo e Análise do Discurso: aproximaçóes e afastamentos na (re) construção de uma trajetória. ALEA 2005;7(2):305-22.

15. Minayo MCS. Análise qualitativa: teoria, passos e fidedignidade. Ciênc Saúde Coletiva 2012;17(3):621-6. 